\title{
CORRESPONDENCE
}

\section{Coal in reserve}

SIR - Robert Olby's article “'Britain's resources of coal and spent uranium fuel", (Nature 29 April; 296 797-801) puts into sharp perspective the opposing arguments about fossil fuels versus nuclear fuels.

For the first time, the previously murky distinctions between the different classes of coal reserves have been made fairly clear. Previous attempts to do this have usually been obscured by the question of the future of coal versus other forms of energy. For example, those who believe that limited government resources should not be invested in the coal industry have tended to use the most restricting definitions of coal reserves, coupled with the lowest figures of percentage extraction, in order to suggest that coal has no future. As Olby points out, referring to A.M. Clarke, the future of coal is hardly unaffected by government policy. However, Olby himself is impartial in the matter of policy; he is simply clarifying the distinctions between different classes of coal reserves.

His brief account of Jevons's much misunderstood work of 1865 is also impressive. Jevons's point is just as valid today and, apparently, just as misunderstood. The finite extent of our recoverable fuel reserves does not define the period of time for which we can exist as we are before we run out of fuel. It defines the much shorter period for which we can continue to expand for the same production-to-fuel consumption ratio. A statement such as "At present rates of consumption, we have enough coal for 300 years" is thus meaningless.

Mr A.M. Clarke, ex-Chief Geologist of the National Coal Board, has probably done more than anyone else in Britain to stir up thought on these issues. It is good to see that his work is acknowledged in your pages, despite the continuing efforts both inside and outside the National Coal Board to denigrate his achievements.

ANTON ZIOLKOWSKI

Department of Mining Engineering, Delft University of Technology,

Delft, The Netherlands

\section{Ball of fire?}

SIR - On Tuesday, 3 August, shortly after 4.00 p.m., the Cavendish Laboratory and the surroundings were struck by lightning several times during an exceptionally intense storm No structural damage ensued, but immediately after one of the discharges a ball of light was seen by a number of observers. Their descriptions are not entirely consistent but certain features are agreed upon well enough to enable a broad description to be given. The discharge apparently responsible struck near the centre of the Bragg Building, which runs east-west. An observer on the ground floor of the Mott Building, whose back was to the window, saw his room momentarily lit as if by a very bright object moving past rapidly towards the west, between the Bragg and Mott buildings. Another observer on the first floor saw the space between the buildings filled with a luminous haze at least to the first floor level, and on looking to the west noticed a bluewhite light that he thought at first was a warning light on a distant tower. $\mathrm{He}$ apparently noticed no motion, but his companion in the same room must have seen it an instant earlier for she had the impression that it was moving past and away, and possibly expanding as it went, being about the size of a grapefruit when first seen. Three people who saw it after that, as it moved over the ground to the west, agreed it looked about the size of the moon, was blue-white in colour, very bright, and was visible for some 4-5 seconds before suddenly vanishing.

To this reasonably well attested observation must be added that while an assistant in the duplicating room, on the ground floor, was closing a small window she was startled by a noise that made her think the window had been knocked in; a bright sparkling object, resembling the lights thrown out by expensive rockets, entered by her head, rebounded from a machine and left as it came. The window was in fact undamaged, and when examined next morning entirely unmarked. Both assistants who were there at the time are convinced something came into the room.

BRIAN PIPPARD

Department of Physics,

University of Cambridge, $U K$

\section{Badgers still snared}

SIR - I understand that the Royal Society for Nature Conservation, while welcoming the ending of the gassing of badgers by the Ministry of Agriculture (Nature 22 July, p.317) because of its inhumanity, is adamant that only badgers that are positively found to be infected with tuberculosis should be destroyed. We learn, however, that snaring of badgers is to continue (which is surely as inhumane if not more so than their gassing) which makes it impossible to test for infection before killing.

Margate, Kent, UK

GWENDOLEN BARTER

\section{Nuclear risks}

SIR - I find the claims of Martin Fodor concerning the dangers of nuclear power (Nature 22 July, p.320) both confusing and inconsistent with the available evidence. Studies in a number of countries have compared the number of fatalities from the routine operations of the complete fuel cycle for nuclear, coal-fired and oil-fired generation. They all show that nuclear generation is at least as safe, and probably a good deal safer, per unit output than using coal or oil. Martin Fodor is quite wrong to imply otherwise.

These evaluations include the contribution from uranium mining to the hazards of nuclear generation. I am not aware of any studies showing 50-100 per cent occupational mortality among uranium miners, but it has been known since the fifteenth century that underground metalliferous mines give rise to enhanced mortality from lung disease among the workforce. Modern radiation safety standards based on the recommendations of the International Commission for Radiological Protection (ICRP) are designed to ensure that working with radiation safety ensures that the main occupational hazard in uranium mining is the physical risk.
Comparative estimates of the routine risks from the alternative energy sources are not so reliably established as for nuclear and fossil fuels. However, such information as is available suggests that the risk per unit generation is within the range of the other fuels. Professor Fremlin has pointed out that the idyllic village millpond has only to account for one drowning every 200 years to be classified as the most hazardous energy source, and generating electricity from wavepower, the renewable resource with which the United Kingdom is most generously endowed, is likely to involve substantial risks.

Rare major accidents invariably give rise to a much smaller death rate than the routine operational risks for all technologies. Despite this, they are of particular concern because of society's abhorrence of multiple fatality accidents. Nuclear electricity generation is particularly well protected against such events: not a single death from radiation has been recorded from any accident during the 25 years such plants have been operating. Whilst the probability of nuclear power accidents is certainly not zero, all the evidence indicates that the risk is much smaller than for many other accepted activities. Anyone concerned about accidents which may kill large numbers of people should worry about technologies other than nuclear power which are over 100 times more likely to cause such accidents.

The overall conclusion can only be that no practicable method of electricity generation is particularly hazardous, nor is any so safe as to merit particular preference. Nuclear electricity generation is certainly not the most hazardous of the technologies we use, and may be one of the safer options.

Safety is only one aspect of the environmental impact of electricity generation. In other respects nuclear power has an inherent advantage because it is the most compact energy resource available. Consideration of land use, visual intrusion, water supply, transport requirements and biological effects, together with the safety aspects, gives good grounds for the view that on balance nuclear power is the least environmentally damaging of the available options for providing the electricity we need.

AERE Harwell, Oxfordshire, UK

BRIAN WADE

\section{Oxygen treatment}

SIR - In view of the recent press publicity, which we understand has embarrassed many neurologists and general practitioners, on the use of hyperbaric oxygen in the treatment of multiple sclerosis, the Multiple Sclerosis Society wishes to state that at no time has it recommended its members to seek treatment with hyperbaric oxygen.

We are awaiting with interest the results of a carefully monitored double-blind controlled study recently undertaken in America with the support of the American National Multiple Sclerosis Society. Upon receipt of the results of this trial the society's medical advisers will immediately review this matter.

JOHN WALFORD

Multiple Sclerosis Society,

London, UK 